\title{
LINGÜÍSTICA Y CINÉSICA
}

o. Antecedentes.

El fenómeno de la comunicación se ha convertido en los últimos veinte años en presupuesto común a ciencias de muy diversa índole, llámense Biología, Jilosofía, Psicología, Matemática, Antropología, etc. ${ }^{1}$.

De todas ellas es, sin duda, la Lingüística la que, por razones obvias, viene ocupándose fundamentalmente del proceso comunicativo humano. En este sentido, la rigurosa formalización del sistema verbal efectuada por la Lingiuística ha permitido abrir su campo de estudio a otros sistemas significantes no estrictamente verbales. Porque, ciertamente, resulta imposible entender el proceso comunicativo humano sin dar cuenta de la actuación semiótica.

De otro lado, la scmiología o semiótica, que, como se sabe, viene siendo desde Saussure ${ }^{2}$ materia de estudio obligatoria para el lingüista, presenta ya, pese a su todavía embrionario desarrollo, toda una pluralidad de sistemas signicos susceptibles de investigación. De entre tan amplio panorama hemos acotado para su revisión, a lo largo de estas páginas, un tipo específico de signos, los signos gestuales.

Iin este orden de cosas, sin pretender atribuir al lenguaje de los gestos una prioridad genética, partiendo, pues, de la superioridad de la palabra

1 Cir. Morris fue de los primeros en observar la importancia bísica de los signos con relación a una amplia gama de saberes. Cf. su Foundations of the theory of signs, Foundations of the unity of science. Chicago, 1938 vol. I, num. 2.

2 'Tambićn en nuestro pais asistinos a una verdadera eclosión de publicaciones relacionadirs con la semiótica, eclosiön que tanto se presta a un análisis de sociologia de la cultura. P'ueden verse, por ceñirnos a publicaciones especializadas, los últimos numeros de lits revistas Prohemio, Filología moderna, etc. I,os términos semiologia y semiólica son emplearlos cn este trabajo como nteoria general de les signosn, prescindiendo de la cliferencia historicanente es!ablecirla

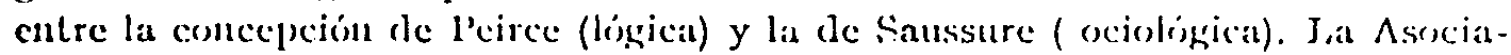
ción Internacional de Semicitica ha arloptado internacionalmente el termino semiólica, considerándolo equivalente, de forma convencional, al de semiologia. 
en el hecho de la comunicación humana, conviene situar en su verdadero lugar otros sistemas no-verbales de la actividad comunicativa: la paralinguiística y la cinésica ${ }^{1}$. Ambas disciplinas, muy próximas en su función comunicativa y también en su inicial desarrollo, forman parte con todo derecho de la elaboración linguiística.

Con el gesto nos encontramos, de entrada, ante la forma más completa de los sistemas comunicativos no verbales. De manera independiente o en interacción con la palabra, todo individuo, sea cual fuere su nivel cultural, manifiesta en la comunicación una conducta cinésica y con frecuencia también paralingüística ${ }^{2}$. Las variantes residen, en todo caso, en los grados de percepción visual, en los difereintes narcos sociales, en el desarrollo corporal y en las condicionantes psicológicas, tanto se trate de gestos espontáneos o intencionalmente comunicativos. $\mathrm{Y}$ este comportamiento corporal, establecido en base a una convención, posee, un significado que liace falta conocer.

'También los medios audiovisuales -televisión, cine-, que tan fuertemente sensibilizan hoy las posibilidades expresivas del hombre, tienen en el gesto (por muy diversas razones: economía de espacio, esquematismo al servicio de una mayor divulgación, etc.), un poderoso aliado.

Pero, aun conociendo la complejidad con que se presenta este material gestual, los trabajos llevados a buen término, especialmente en Iirancia y Norte-América, muestran que es factible hablar, tal como en su día hizo la Linguística General, de unidades mínimas gestuales con posibilidades combinatorias según unas ciertas leyes. Leyes a partir de las cuales cabe aceptar el gesto como un lenguaje o un cuasi-lenguaje, como prefiere denominarlo Yuen Rem Chao, por poseer sólo algunas de las propiedades del lenguaje ordinario.

Así, el considerar la manifestación gestual como un sistema de signos que se combinan y ordenan de acuerdo con un código específico, ha permitido a Ray I. Birdwhistell - del que nos ocuparemos in extenso a renglón seguido- llegar a una primera formulación básica para el desarrollo de la cinésica. La comunicación no se concibe ahora en una dimensión lineal viendo en el lenguaje verbal un único medio de

1 Hemos adoptado el tírmino 'cinćsica' y sts derivados (del inglés Kinesics) frente a las versiones, que también pueden leerse en catellano, Kinésica, Kinema, eteétera, por parecernos mís de acuerclo con la traducción a nuestra lengua de otrus témuinos con illéntica raiz: cincmatógrafo, cinemática, etc.

- Como aportation bisica, cf. Cor, Curkey, On Inunan Commnnication, New York, igor. Asinismo, R. I. IBndivinstri, I, Paralanguage: 25 years after Sapir (en Le:tures on experimental Psychiatry, Uuiv. of Pittsburgh Press). 
expresión: se trata más bien de un conjunto expresivo perfectancnte organizadlo en el que diversos códigos se manifiestan en interdependencia y se influyen mutuamente. Desde este ángulo la gestualidad se prescuta como un estrato más de la dimensión multi-canal del proceso comunicativo litumano.

$\Lambda$ dmitido, pucs, el carácter autónomo del comportamiento gestual, la cinésica se sitúa, según la definición propuesta por el mismo Ray L. Birdwhistell ("la cinésica como metodología trata de los aspectos comunicativos del comportamiento, tomado $\mathrm{y}$ estructurado del cuerpo en movinienton), al margen del conductismo y la teoría de la información. Su campo de estudio abarea el amplio repertorio de actos corporales humanos que intervienen en la commincación, no sólo los llamados propiamente gestos -manifestaciones corporales que implican movimiento- sino toda la vasta gana de actitudes corporales comunicativas más estáticas: la expresión facial y la postura. Iis precisanente con relación a esta última clase de actos cinćsicos donde la escucla francesa se aleja de los postulados de la cinćsica norteamericana. Si bicn anbas adniten que, para estudiar un comportamicnto humano como signo, es necesario conocerlo cualitativamente en el nivel significante de tal signo - tal como lia hecho la cinésica-, la escuela francesa insiste en la dificultad de identificar las unidades del plano de la expresión. A diferencia de la doble articulación propia del lenguaje verbal, el comportamiento significativo en la postura corporal se nos of rece, en principio, en una sóla articulación. Lis verdad que hay un primer paso respecto del conociniento cualitativo de las unidades gestuales al que la cinésica ha respondido ampliamente. Alora bien, si se admite que la acepción de gesto no implica necesariamente movimiento, toda vez que un gesto puede ser el resultado de un conjunto de actitudes físicas, la investigación francesa se pregunta bajo qué condiciones debería darse en el lenguaje gestual la doble articulación lingüistica y qué unidades del programa gestual serían equivalentes al monema de la lengua.

Pero no es éste el lugar para introducirnos en el complejo campo de la escuela francesa ( $y$ utilizamos el término con toda reserva), por más que ello iluminaría a su vez algunas de las cuestiones más debatidas en el marco de la cinésica norteamericana. Apenas señalo aqui el carácter asistemático que rige la aplicación en el dominio gestual de autores y teorías lingüísticas por parte de la escucla francesa. Donde, hasta el momento, se ha logrado una sistematización más rigurosa del material gestual, tanto por la continuidad de trabajo como por la uniformiclad de criterios y metodología es en el ambito de la mencionada escuela cinésica norteamcricana. 
No faltaban razones para que fueran precisamente los lingüistas norteamericanos quienes iniciaran el desarrollo de esta vertiente semiológica. Iras peculiares condiciones sociolingüísticas de las culturas indias y la trayectoria seguida por la lingiística norteamericana en los últimos cincucuta años con 'lrager, Bloomfield y Sapir a la cabeza, abonaron el campo del mejor modo para el nacimiento de la actual investigación cinésica. La distinción llevada a cabo por Sapir entre cultura y personalidad permitió a la lingüística penetrar en el complejo mundo de las relaciones que median entre una y otra ${ }^{1}$.

Gran parte de la investigación paralingüística y cinésica, incluso la que procede de la vida cmocional - que es la que en mayor medida se comunica mediante el lenguaje no-verbal- se halla, por universal que parezca, conformada por las mais estrictas convenciones sociales. lin tal sentido, las aportaciones de psicólogos y psicolinguiistas, desde un Ii. Boas a sus discípulos, M. Mead, C. Osgood, resultaron esenciales para estar investigación ${ }^{2}$.

Recogiendo, pues, los materiales heredados de sus predecesores, la cinésica estableció, en un primer momento de análisis, las dependencias entre lo que cra significativo y no significativo de la postura, mímica de la cara y movimiento del cuerpo. lista dependencia metodológica de la cinésica con respecto a los criterios de análisis de la Linginística General, ha proporcionado a la cinésica tanto sus mayores logros como sus más grandes limitaciones. Porque paralela y paradójicamente al reconncinicnto de la autonomía del código gestual, la cinésica viene sirviéndose de un método ajeno a su propio objeto.

'l'an es así que, al tiempo que '́rager y Smith trabajaban en los años cincuenta en el ámbito de la Pre-lingüística valorando los aspectos

1 Jil mismo Sapir supo ver también el paralelismo que se da entre ciertos niveles rle lengrua y el comportamiento motor del cuerpo liumano: "Respondemos a estos [gestos] con una rapiclez tal, que casi podría decirse que lo hacemos de acuerclo con un código que, sin estar escrito en ningún sitio, ni ser conocido por nadie, es comprendido, sin emlsargo, por todo el mundon. (Y). SAPIR, Selecled Writings of E. Sapir (David G. Mandelbaum), Univ, of California P'ress, Berkeley and Los Angeles, 1949. pp. 533-543)

2 Remitimos al trabajo tan reiteradamente citado de W. LAA BARRF, incluido en el libro Approaches to Semiotics, editado por Sebeok, Hayes y Bateson, La Haya, I964. I a Barre, a propósito de una modalidad cinésica como la risa vinculada aparentemente a la personaliclad inclividual, nucstra los condicionamientos indivirluales inherentes a su manifestación. Fenómeno, pues, que está sometido a convención, diferente schin el contorno sociocultural y eclucativo de que se 1 ate, conno lo demuestra el humor joropio de cada pais, tan arraigado como las

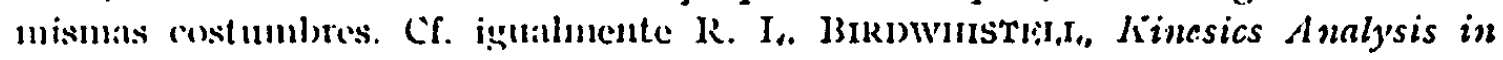
the Inicstigation of the limotions, en lixpression of the Emotions in Man, International liniv. I'ress, 1963, pp. 123-139. 
físicos y biológicos no incluidos en el componente fonético, sintáctico y semántico, la cinésica acotaba en la I’re-cinésica los aspectos fisiológicos que condicionan el comportamiento motor del cuerpo humano. Los resultados del trabajo de 'lrager sobre Para-linguiistica muestran hasta qué punto tienen que ver los unodificadores vocálicos" o las "cualidades de la vorn con las variaciones de intensidad, duración, ete., del hecho cinésico.

Muchos de estos movinientos incluidos en la l're-cinésica fucron desestimados en el primer nomento del trabajo por considerarlos tan solo de interés neurofisiolúgico y en consecuencia carentes de significado. Lin el curso de la investigación estos movinientos recobraron todo su valor al comprobar el control social que regín muchos de ellos. Lil acto de estirarse, por ejemplo, realizado por un estudiante norteancricano en el interior de un aula, resulta inconcebible para un universitario español. ¿Quicre esto decir que la difercncia de un comportamiento es debida a razones de fatiga, cansancio, etc.? Más bien se trata de convcnciones sociales, de acuerdos tícitos de sociedades distintas.

\section{I'recinésica.}

De las diferentes unidades mínimas de movimiento aislable cada sociedad elige, selecciona unas variantes determinadas que, a su vez, usa en situaciones específicas, en correspondencia con los distintos niveles de lengua. Y sicndo el sonido articulado el material universilmente válido para la cmisión del habla, cadla lengua posee un número propio de fonemas que la caracterizan como idiona. be forma que la cinésica, tras los resultados obtenidos con la aplicación cmpírica de sus teorías al inglés americano, alcrta sobre la importancia de un análisis semejante que diversilique "hablas" gestuales y revele los límites de la universalidad del lenguaje gestual. I,o cual apunta, además, hacia la necesidad de un aprendizaje gestual paralelo a la aclquisición de mina lengua ${ }^{1}$, si queremos conocer en profundidad el sistema lingüístico de un idioma ${ }^{2}$.

1 In relación con la adquisicion de gestos collificades por culturas y ambientes sociales están pensadas ciertas técnicas modernas de adaptación que, aprovechadas preferentemente por el mumdo del comercic y las relaciones puiblicas, adiestran al individuo en el comportamiesto corporal propio del medio cn que deba integrarse.

2 Iil interés que revela un análisis gestual para completar el estudio lingüistico de wn idloma no es de alora mismo. Iin castellano piénsese en el tratanicnto del tema por cl inagotable Junn IIuarte de San Juan tal y como señaló (jrícorokio) Maka Ñón en sus Ensayos Liberales. Iin la actualidad merece observarse comos el acereminiento al sistema gestual desche muy distintas perspectivas converpe, sin cmbargo, en el irea de la propia cincisica. I'ttecle verse, por citar un ejenuplo recicntemente verticlo al castellano, el articulo de lirank $\Lambda$. Tin,man publicado 
A este respecto, el que nuestra percepción, de manera ilusoria, haga uniformes muchas de las variantes no sólo de lo que se entiende por gesto, sino de cada uno de los elementos que intervienen en su articulación, no es obstículo para que se establezca una evidente analogía entre la actuación cincisica y el acto del habla. Y ello, no tanto cn función de la equivalencia de las unidades inherentes a ambos sistemas, como por la estructura que los sostiene ${ }^{1}$.

Tales son los supuestos fundamentales de quien, tras los valiosos hallazgos de C. F. Voegelin y W. C. Stokoe, ha logrado conciliar lo que hasta él se desbordaba en intentos de muy diversa fortuna. Y nos estamos refiriendo al mencionado Ray L. Birdwhistell. La solidez de que gozan sus teorías nos incluce a prescindir aquí de la anterior investigación cinésica por considerarla, en cierta manera, asumida en los trabajos del mismo Birdwhistell.

Paralelamente al "corpus" verbal elaborado en su día por la I,ingüística General con el material sonoro de la lengua, la cinésica establece unas unidades mínimas de movimiento perceptible, aislables de la cadena gestual, a las que identificó como "cines"-kines-. Su valor, al igual que en la roz, les vicne dado por la peculiar manera de combinarse con otros clementos de la cadena gestual. Los elementos cualificados en una serie cle rasgos diferencian los cines en "cinemas" -kineme-, es decir, los fonemas de la lengua, mientras que los "alocines" -allokine-, como variantes del cine, tienen idéntica función que los alófonos. Asimismo, las formas cinemórficas completan las unidades propias del nivel fonético y fonológico.

en liciisla de Occident: (minl. 90, septiembre cle 1970): De la parcepción de las personas. Lil enfoque filosúfico del autor no excluye el siguiente ulescubrimienton de la cincisica: Nivestra percepción de los estados expresivos de los demás se basa en discrininaciones muy sutiles de los movimientos de cejas, pestañas, boca, inclinaciones de la cabeza, movinientos de las manos y los dedos, posturas de cuerpo, entonaciones, sonidos no verbales y su contexto. Lil proceso por el cual se adquiercn habilidarles parece ser tan complejo como el proceso de la adquivición del lenguaje. No existe una ciencia de los movimientos corporales semejante a la gramitica y, sin embargo, como hemos demostrado, el niño es capaz de hacer discriminaciones de percepción de un orden muy refinado; hay en ello ma analogia con el aprendizaje para diferenciar distinciones gramaticales complejas, por ejemplo entre "Juan quiere a Maria" y "Maria quiere a Juans. Tis concebible que pueda construirse, partiendo de los movimientos corporales, un sistema de segmentación antílogo a la granlitica." (p. 273).

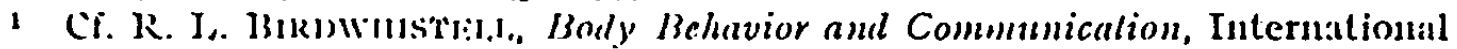
lincyelopelia of the Social siences, New York, vol. 3, 1960. Hay que señalar que tamproro faltan quienes nieginn torla correspondencia -entiéndase bien comesponlencia y no depenulencia - con respecto a cualqutiera de los niveles scritaladus. 
Desde esta premisa básica la cinésica se propuso determinar el sentido del material gestual atendiendo al sistema que imprime a sus unidades un valor especifico. lin este orden de cosas son muy importantes las estadísticas que han sido elaboradas decribiendo los elementos mínimos de significación y su respectivo valor según culturas.

\section{Microcinésica / Macrocinésica.}

De cualquier forma, es fácil reconocer la complejidad que lleva consigo la elaboración de una sintaxis gestual. I'uesto que podemos distinguir con toda claridad movimientos que identificamos como gestos de aquéllos otros que consideramos como prácticas desviatorias de un individuo, bien se puecle decir que la función sintagmática del movimiento, el cincsintagma, es lo que determina la significación del gesto. Una misma inclinación de cabcza significando "saluclo", si no va acompanada de ciertas reglas de velocidad, amplitud, etc., puede interpretarse de muy distintos modos: el mismo gesto expresari, según su contexto sintagmático, desde un deseo de agacliarse hasta un sentimiento de vergüienza o sunisión. Se impone, pues, la delimitación de los elementos de esa sintaxis gestual: tipo de rasgos que la componen $y$, en consecuencia, su significación.

$\Lambda 1$ mismo tiempo, y por lo que respecta a su función semiótica, cn un comportamicnto significativo no-verbal la expresión se presenta según rasgos codificaclus de forma que su significación le vicne dada por el código en que se encuentra inmersa. Lin el ejemplo anteriormente citado, si el acto comminicativo de la persona que se inclina ante otra no va acompañado de determinado comportamiento facial, de cierta regularidad en el movimiento, todo ello queriendo significar "respeto», su significación, al quedar fuera del código ético que le imprime tal valor, es muly diferente.

Issta clase de expresiones no guardan con su contenido una relación scmiótica necesaria, como en esta ocasión "respeto". Pero incluso esos sistemas, simples por su identidad de estructura, reciben codificaciones muy diferentes si se combinan con otros rasgos significativos.

Ias fúrmulas de saludo se realizan de distinta manera según las jerarquías sociales. Una persona de clase alta prefiere saludar, en ocasiones, con una inclinacion de cabeza frente al uso popular del apretón de manos. De otra parte, un mismo moviniento realizado de forma 
iterativa convierte este acto en proceso, con lo que ya su significado inicial difiere radicalmente del primero.

Naturalmente, el reconocimiento de los grados de diferenciación gestual y asinismo de la actuación semiótica en la comunicación vaŕa no sólo por culturas y nivcles sociales sino en el propio individuo. Pruebas experimentadas en grupos de personas, como la tan reveladora de las posiciones del ojo ${ }^{1}$, permitieron diferenciar las clases de movimiento que ejecuta un individuo en su "capacidad generativa" a la manera del lenguaje verbal, es decir, en un comportamiento «idiocinésico».

Pero, paralelamente al descubrimiento de las reglas sintácticas que dirigen el comportamiento cinésico, Birdwhistell, merced al estudio comparativo del lenguaje verbal y aprovechando los datos etnográficos que se le ofrecían, ha comprobado cómo lo que popularmente conocemos por gestos son en realidad formas incapaces de un funcionamiento autónomo. Las "formas ligadas" tienen su equivalente en los infijos, prefijos, sufijos... del lenguaje articulado.

Desde otra perspectiva, se han delinitado también varios niveles de estudio según se opere con unidades cinésicas simples o complejas.

Una primera categoría de análisis - sin retrotraernos a la anteriormente mencionada Pre-cinésica- está representada por la Micro-cinésica. Lo que Birdwhistell incluye aquí son los tipos de cines y sus posibilidades combinatorias. En tal apartado, se sitúan los tres cinemas fundamentales de la estructura cinésica americana que no contará, según las predicciones de Birdwhistell, con más de cinco unidades básicas.

I a organización más compleja de estas formas reveló en el curso de las investigaciones que las construcciones cinemórficas estructuradas en su nivel más alto remitían también a las unidades superiores del discurso verbal tales como palabra, frase o parágrafo. De esta manera, la formalización de los elementos del cuerpo humano en la comunicación daría razón nuevamente del paralelo estructural con el lenguaje hablado.

\section{Discurso verbal y cinésico.}

Sin duda, la parte más sugestiva de la obra de Ray I. Birdwhistell deriva de su habiliclad para analizar el discurso desde el punto de vista verbal y cinésico a un tiempo. Liste trabajo es tanto más reve-

1 R. L. BIRDIWIISTlir., op. cit., vol. 8, pp. 370-385, 1968. 
lador si pensamos que las tesis cinésicas más comprometidas se situan a este nivel comunicativo, que es precisamente el de mayor interés para el lingiiista!.

Iil individuo, en su esfuerzo comunicativo, se procura un comportamicnto corporal determinado para aytudarse en la enisión del nensaje. Pero, adcmás, la conducta corporal que manifiesta no siempre se da de acuerdo con la significación de sus palabras, de manera que los gestos pueden denunciar aquello que voluntariamente oculta la expresión propiamente lingüística. Iil comportamiento cinésico, como auxiliar del lenguaje vocal, traduce estructuras profundas y conceptos mentales inconscientes. Y hacia el análisis de ese comportaniento se dirigen los trabajos más recientes de la escuela cinésica norteamericana ${ }^{2}$.

Igualmente, habida cuenta de las interdependencias mútuas de los canales verbal y cinésico, hoy son perfectamente controlables un cierto número de variantes cinésicas asociadas al lenguaje verbal, pese a la aparente falta de regularidad con que parece mostrarse este tipo de actuación semiótica. Con estas formas integradas en la Macro-cinesica tienen que ver ciertas variantes agrupadas en criterios de intensidal, duración y amplitud del niovimiento, cuya medición interesa para completar el sentido del mensaje tanto cinésico como verlual.

\section{I. Paralingiiislica y'paracinésica.}

Por otro lado, también una vez más la cinésica se equipara a la Linguística cu su necesidad de conocer el comportamiento "praracinésicon del hablante-actor. Jistas scñales paracinésicas lan sido probadas como elementos relerenciales del discurso cinésico en cuanto lo modifican de una u otra manera.

1 Una caracterización del gesto acompañando a la palabra en una zona geográfica concreta puede verse a través del estudio realizado en l'rancia entre I950 y 1952, que recoge R. CRESSWir, en Pratiques et Langages gestuels (Langages Io), Paris, I968. Número éste verdaderamente ejemplar para seguir el actual curso de los estudios gestuales - 110 obstante datar de 1968- a la vez que muy útil por la abundante bibliografia que incluye sobre el tema.

2 Las investigaciones se llevan a cabo en centros de psiquiatria (Easterm Penusylvania I'sychiatric Institute) a un tiempo por psicólogos, sociólogros $y$ lingüistas. Ia proyección terapéutica no nos interesa aqui, por mís que aclare enormenente el comportamiento lingüistico de los humanos. Remitimos a los interesados a los trabajos: R. I. IBumwinstid, The dmerican I:amily: an idealized model, en liamily Service llighlighls, New York, March, 1970, XXXI, num. 3. 11). 75-79, 97-98; Critical Moments in the I'sychialric Inlcrwicte, ch liescarch Approaches to a Psychiatric Problem. Illinois, IgG2 (Galcsbury Symposium). 
De forma análoga a como el hablante se vale de indicadores vocálicos (piénsese en el tan frecuente Mm...Mm..., E...E..., usados en español como nexo, sobre todo en periodos verbales amplios) Birdwhistell ha llegado a encontrar y a analizar exhaustivamente los indicadores agrupados según su peculiar función como coordinadores sintácticos de periodos verbales o de la misma cadena cinésica. Seguramente, son los indicadores gestuales los que inician y acaban el discurso hablado, e incluso, caracterizan su totalidad cerrando o dando entrada a sus interlocutores.

Particularmente importante para la comprensión del lenguaje verbal en escenas de grupo, son los indicadores que dan cuenta no ya del cntorno de la frase sino del contexto del discurso. Normalmente, el comportaniento cinésico $y$ verbal seguido por el hablante ante otros individuos está modificado según compartan o no sus miembros la ejecución de esas mismas actitudes corporales. De forma que, para llegar a descifrar la totalidad del mensaje, es preciso no omitir la conducta de los interlocutores entre los que se produce la comunicación ${ }^{1}$.

Una nueva prueba para cutender la correlación entre los actos verbales y no verbales viene dada por cierta clase de unidades cinésicas encargada de la acentuación cinésica propia del idioma de que sc trate. Concretamente en el inglés americano existen cuatro "cinemas supra-segmentales" (acentuación primaria, acentuación secundaria, no acentuación y desacentuación) encargados de marcar combinaciones entre las diversas partes de la oración: adjetivo y nombre, verbo y adjetivo, etc. listos cincmas están dotados de una función sintagmática que también puede actuar coordinando períodos demasiado largos.

Quizá sólo un estudio comparativo de varias lenguas con su propio carícter cinésico - Birclwhistell hace notar las diferencias cinésicas de una misma persona a la hora de liablar distintos idiomasaclarará del todo la todavía inmadura sintaxis gestual. En el caso del español, tratándose de una lengua en la cual la riqueza acentual supera con mucho a la del inglés, su análisis revelaría una gama de acentos consecuentencnte mayor que en aquél.

Igualmente aclaratorias son las experiencias llevadas a cabo en torno a la frecuencia con que aparecen determinados hechos cinésicos asociados a distintas clases de elementos léxicos. Este tipo de indicadores sólo cobran sentido en conexión con la unidad léxica a la que

1 I a I.ingiiistica conoce ina rigurosa formalización de los elementos que integran la frase y de sus leyes sinticticas, pero apenas se ha pronunciado todavia en lo que concierne a la totalidad del discurso, para lo cual tendria que atenderse particularmente a la l'ragmaitica de Morris. 
acompañan. Birdwhistell habla de indicadores pronominales para aquéllos que acompañan o sustituyen a esta tipología del léxico con una articulación que difiere según la mayor o menor distancia hacia el objeto - asunto percibido, ya sea real o simbólico: éste, ése, aquél, etc. Junto a éstos, los "indicadores de pluralización»: nosotros, ellos, etc, los que indican modalidad, tal como: despacio, cuidadosamente, rápidancnte; o arquéllos que indican espacio o distancia: "Voy a coger un taxi".

Iistos indicadores cinésicos tendrían una posición que podría ser significada como propia de la Macro-cinésica, o dentro del sistema semiótico, como perteneciente a la supra-linguística o supra-cinésica. 'Todas ellas se describen con arreglo a principios generales que nos remiten, por otro lado, a nociones fonćticas. Ie aquí tales principios:

a) Sus propiedades articulatorias son abstraidas por clases oposocionales del comportamiento.

b) Iistals unidades aparecen en contextos sintricticos distintivos, es decir, que su clasificación les viene dada por el tipo léxico al que acompañan.

c) lixisten oposiciones situacionales de articulación que limitan 1a posible confusión de las señales.

d) Cuando no sea posible distinguirlas en su articulación, se recurrirá a oposiciones sintácticas del entorno.

Todas estas unidades están, pues, dominadas por contextos lingiiisticos particulares.

\section{Nolación cinésica.}

Por lo que afecta al procedimiento de notación para ésta y las restantes clases de elementos cinésicos, se viene recurriendo al sistema simbólico, toda vez que lo primero que echa en falta el investigador es un lenguaje analítico adecuado al objeto que le es propio. La pobreza y falta de precisión con que nos expresamos en tomo a los gestos, lenuncia la ausencia de un vocabulario específico que satisfaga la descripción gestual. İn tanto el sistema de notación simbólica asegura cierto grado de objetividad en el análisis, al tiempo (que erita una excesiva exhaustividad que dificultaría el manejo de sus unidarles ${ }^{1}$.

Una cuestión que Birdivhistell a lo largo de sus trabajos ha destacarlo con fuerza es la importancia del tipo de código que emite d mensaje,

1 Con respecto a la notación cinésica y ch lo que se reficre a los marcarlores pronominales, un $k^{\prime \prime}$ scria idcontificalo: $K=$ cincisico, $p:-$ pronombre; frente a ellos el término $K^{\cdot n}$ se usa para designar los marcalores de pluralización. 
insistiendo así en la extremada precaución con qute el lingüista y el cinesiólogo deben mancjar los hechos de comunicación seleccionados para sú análisis. Al estudiar una modalidad comunicativa, no se puede perder de vista que tratamos con datos aislados intencionadamente de un solo canal entre los varios que intervicnen en ella. De esta forma, las relaciones de dependencia que median entre la estructura lingüistica y cinésica - sólo estudiada hasta el momento en el inglés americanono resultarán fáciles de establecer sino en un futuro de la investigación. Con relación a ello, la cuestión tantas veces debatida de la "redundancia» está lejos de aparecer resuelta aquí tal como fue tratada por la teoría de la información, en la que un mensaje emitido por varios códigos a la vez aumenta su número de probabilidades ${ }^{1}$.

\section{El gesto en inler-acción con la palabra.}

Refiriéndonos ahora con detalle a algmas clases de gestos, entre los que ilustran da palabra, destacan con mucho la expresión facial y el movimicnto de las manos, juzgados éstos por Lifron como "batutas» e "idcógrafos". En la gestualidad manual se incluyen, además de las manos, cuya significación difiere según que alternen o ejecuten el movimiento conjuntamente, los movimientos de brazos y hombros por considerarlos como una prolongación de la movilidad manual. El tipo "batutas" marca el tiempo de la locución verbal, destaca, acentía etcétera, frente al tipo idcógrafo, que señala la dirección que el pensamicnto expresa por la palabra ${ }^{2}$.

liste segundo tipo versa sobre muchas de las circunstancias que rodean la manifestación de habla, tales como el tipo de información de que se trata $u$ otras condiciones externas. Naturalmente, un conferenciante o un locutor de televisión ejercerá un mayor control sobre su comportamiento cinésico que unos amigos en una tertulia de café o un locutor de radio. Iin todos los casos el informado se esforzará por ver al informante para conseguir una comunicación completa.

1 Cf. R. I. BuRvWHISTli,I., Kinesics, inler-and Inlra-Chanel Communication rescarch, en Studies in Semiotics, Social Science Information, Paris, December, IgOS, VII, pp. 9-26.

2 Un buen ejemplo de todo lo dicho es la descripción del extraordinario Sergio Celibidache en la pluma de F. Hiokziri,n, La magia de la batula. Barcelona, 1958: "Canta, silba, sisca y gruñe tan fuerte durante la ejecución, que se le oye desde el centro del patio de butacas. Sus pics marcan un ritmo sincopaclo como

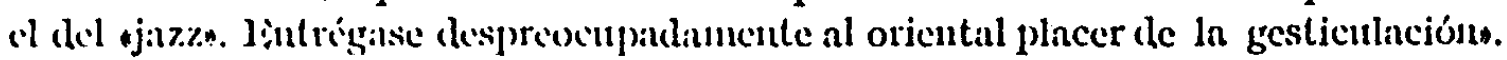

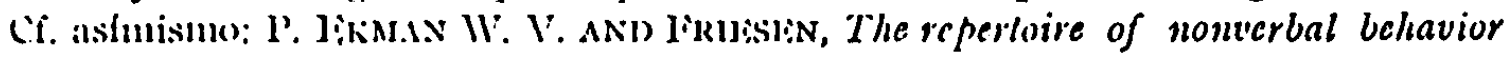
caligorits, origins, usage and colling, Semiotica, I, I (rg69). 
Ante estas consideraciones - por más que demasiado someras- al lector se le habrá venido ya a la mente ese otro intelectual norteamericano preocupado también por la percepción visual: Me Luhan. Ya es significativo que la distancia que media entre la primera obra de MC I,uhan The Mechanical Bride (I95 I), y la primera de Birchwhistell (1952) sea tan escasa ${ }^{1}$. Iúc aquél uno de los primeros estudiosos americanos interesado en valorar los medios de comunicación de nasa, "las extensiones del hombren, tanto en su aspecto formal como en su contenido e impacto en la sociedad.

\section{Léxico gestual.}

Capitulo aparte merecen las consideracioncs de la cinésica alrededor del léxico gestual. $Y$ aunque en este punto las tesis cinésicas se pronuncian con bastante cantela por la tendencia, tan tentadora por otro lado, a atribuir significado a lo que sólo son clementos estructuratess del gesto, se conocen ya monografías léxicas que nos hablan de una scmántica gestual propia de cada sociedad. Nombres como I'ora L. Bailey's o George Devereux, Vocgelin... han contribuido al estudio de los gestos que constituyen el argot del camionero o del mercader americano. Pertenecen a esta tipología léxica aquellos gestos simbólicos que sustituyen con frecucncia al lenguaje verbal y cuya articulación completa equivale a una palabra - los índices-, a una frase - "quédate quieto-" o a todo un discurso. Son, siguiendo a Prieto, de la dimensión del sema, equivalentes, pues, a un enunciado del lenguaje verbal pero nunca a una palabra. Ya Bloomficld, refiriéndose a ellos, reconoce que "hiasta cierto punto los gestos de los individuos son convencionales $y$ diferentes en cada diferente comunidad" ${ }^{2}$. $Y$ de tal tipología léxica contamos incluso con listas claboradas a modo de diccionario que tipifican muy bien a países, clases sociales, sexos y edlades. De todo lo cual da buena cuenta nuestra geografía, en la que cada región es una personalidad distinta no sólo a nivel de habla sino en su conducta cinésica ${ }^{3}$. I a án

1 Quizi valga la pena, siquiera sea en función del desconocimiento que todavía pesa hoy en lispaña sobre el nombre y la obra cle RAY J. Bindwusteir., referimos a sus dos obras fundamentales: Introduction to linesics, I,ouisville, University of Louisville Press, 195.4 ( $\mathrm{t}^{\mathrm{n}}$ edición: 1952) y Kinesies and context: essay's in boly motion communication, University of l'eunsylvania l'ress, Phila.

2 I. 131,00minis, Le Langage, Paris, 1970, pp. $4^{1-43}$.

- Iin la actualiclat preparamos una aproximación al lenguaje gestual a través del testimonio de la litcratura cspañola en la corleya de que cllo sujomelrá nes scilo un mevo conociniento del comportamicnto cinesion del hispanoablante, sino man mejor comprensión de nucstra literatura: autores, movimicntos, etc. 
dentro de la distinta clase léxica, además del gesto rítmico que se continuía en toda la secuencia hablada, cabe referirse a otra clase de gestos equivalente a la clase de signos que primero Peirce y luego Morris designaron como icónicos ${ }^{1}$. Listos gestos descriptivos agrupan todas aquellas expresiones corporales que reproducen por lo menos ciertos aspectos de la realidad. Lil juego de los niños es particularmente significativo de tal tipo de gestos; un niño que juega a los aviones tratará de initar con sus movimientos y posturas el objeto a que hace referencia. (Subrayamos "referencia" puesto que la relación semiótica de sus símbolos no se establecen entre la expresión y el contenido sino entre la expresión y el referente). Girará sobre sí mismo con el brazo y la mano extendidos hacia lo alto, representando con los dedos en posición horizontal la forma del avión, $y$, muy frecuentemente, este acto irá acompañado de manifestaciones paracinésicas tales como ruidos onomatopéjicos ${ }^{2}$.

Jil tipo de gestos que describe sucle posecr un carácter bastante limitado de formas en el uso cotidiano. Su carácter denotativo sirve muy bicn a los relatos que se expresan por medio de imágenes, especialmente fijas. En la narración donde la imagen desempeña el papel fundamental y la escritura no es más que un medio auxiliar, se aprecia muy bien la nota repetitiva expresando sobre todo las situaciones más elocuentes. Por su papel "funcional" - según la denominación de Barthesson ejecutados de manera idéntica por los personajes más dispares dentro de una misma situación, sea esta de júbilo, cólera, miedo, deseo, etc.

lín el complejo campo de la semántica, la cinésica permanece expectante ante las conclusiones a las que progresivamente va llegando la lingiiística. lis de esperar que la subcategorización del léxico que actualmente se está llevando a cabo desde los enfoques lingüísticos más diversos, especialmente en lo que se refiere a los verbos, arroje muchos datos de interés para la función cinésica. Una vez que contemos con una tipologín semántica de esta índole, un gesto como uarrugar la nariz" llevaría ciertos rasgos que los situarían en un lugar especifico de la actuación semiótica que interviene en la comunicación.

\section{La proxémica.}

En anńloga dependencia a la tan reiterada lingiústica y cinésica encontramos otra joven disciplina, muy próxima a la cinésica. La pro-

1 lintre lans posteriores aportaciones al estudio de los signos icónicos citemos, por cjemplo, la de bambir'o l:co en el mum. Is de la revista Communications, l'aris, I070.

= Cf. Bunn,1:k, Teoria del lengnaje, Madrid, I967, pp. 296-325. 
xémica, orientada a descubrir la estructura significante del cucrpo humano se incluye asimismo en el ámbito de la semiología. Lin este sentido el acto proxémico, lo mismo que el cinésico, se reconoce como un acto sémico. I a proxémica americana, a pesar de sus toclavía escasísinas publicaciones, analiza los comportamientos de traslación del cuerpo humano dentro de un contexto, a fin de clarificar la dimensión simbólica consciente del individuo al estructurar el espacio.

El cuadro de espacialidad enriquece considerablemente el sentido del gesto porque, en efecto, la comunicación supone como minimo un receptor que delimita, de alguna manera, el espacio gestual del enisor. Un caso extremo de la necesidad de contar con el acto proxémico y cinésico son las acotaciones escénicas. El autor se ve obligado a dar en un aparte las distancias, los movimientos, la mímica de la cara y posición que deben controlar los actores. Aquí reside también la mayor diferencia entre el lenguaje hablado y la escritura.

\section{Perspectivins.}

No es preciso insistir mucho sobre la dirección que en la actualidad presida a la investigación lingülstica anpliando de varios modos el enfoque de su objeto. 'Tanto la proxémica (que roza más a la antropología que a la lingüística ${ }^{1}$ ), como la neurofisiología ${ }^{2}$, la sociología o la comunicación prehumana, ponen a prueba el rigor de las teorías linguiisticas al enfrentarse con muchos de los problemas que de ellas emanan y de las que la lingüistica debe dar cuenta si aspira, como lo hace, a la múxima generalidad de sus hipótesis. Podrá objetarse -como se ha hecho- que, por el momento, el apartado "signo" trabajado por la cinésica no hace sino acumular explicaciones estructuralistas en torno a la actividad gestual sin descubrir las verdaderas raices que las sostienen. Pero el camino ya ha sido iniciado, y no son nada despreciables las tésis y el método de esta escuela lingüística a la que se deben - no obstante todas sus limitaciones- los más recientes hallazgos para, en la intención de Artaud: "Averiguar si en el dominio del pensamiento y la inteligencia no hay actitudes que escapan al clominio de la palabra, y que los gestos y todo el lenguaje del espacio alcanzan con mayor precisión! ${ }^{3}$.

\section{Iistimer TORREGo}

Departamento de Fionética del C. S. I. C.

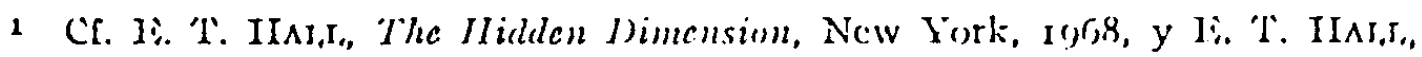
A Systcm of Nolation of l'roxemic Bchauior, en American Anlhropologist. tomo 6,g.

2 Cf. Brain and Behavior 2: Percepcion and Aclion, Middlexes, 1969, Lingland.

- A. ARTAUD, El teatro y su doble, I il Iabana, 1969. pp. Ioo-1ox. 